\title{
Evaluation of Human Disturbance on the Activity of Medium-Large Mammals in Myanmar Tropical Forests
}

\author{
Giacomo Cremonesi ${ }^{1, *(\mathbb{D} \text {, Francesco Bisi }}{ }^{1,2}$, Lorenzo Gaffi ${ }^{2}$, Thet Zaw ${ }^{2}$, Hla Naing ${ }^{3}$, Kyaw Moe ${ }^{3}$, Zarni Aung ${ }^{3}$, \\ Alessandra Gagliardi ${ }^{1,2}$, Lucas A. Wauters ${ }^{1}$, Damiano G. Preatoni ${ }^{1}$ and Adriano Martinoli ${ }^{1}$ (i) \\ 1 Environment Analysis and Management Unit, Guido Tosi Research Group, Department of Theoretical and \\ Applied Sciences, University of Insubria, Via J. H. Dunant, 3, 21100 Varese, Italy; \\ francesco.bisi@gmail.com (F.B.); alessandra.gagliardi@uninsubria.it (A.G.); \\ lucas.wauters@uninsubria.it (L.A.W.); damiano.preatoni@uninsubria.it (D.G.P.); \\ adriano.martinoli@uninsubria.it (A.M.) \\ 2 Istituto Oikos, Via Crescenzago 1, 20134 Milano, Italy; lnz.gaffi@gmail.com (L.G.); \\ thetzaw.1190@gmail.com (T.Z.) \\ 3 Wildlife Conservation Society, Myanmar Program, No. 12 (B-21,22) Narnattaw Road, \\ Shwe Kainnayi Housing, Kamayut Township, Yangon 11041, Myanmar; hnaing@wcs.org (H.N.); \\ phonemyat.moe@gmail.com (K.M.); zarni.wcs@gmail.com (Z.A.) \\ * Correspondence: cremonesi.giacomo@gmail.com or gcremonesi@uninsubria.it
}

check for updates

Citation: Cremonesi, G.; Bisi, F.; Gaffi, L.; Zaw, T.; Naing, H.; Moe, K.; Aung, Z.; Gagliardi, A.; Wauters, L.A.; Preatoni, D.G.; et al. Evaluation of Human Disturbance on the Activity of Medium-Large Mammals in Myanmar Tropical Forests. Forests 2021, 12, 290. https://doi.org/ $10.3390 /$ f12030290

Academic Editor: Pavla Hejcmanová

Received: 29 January 2021

Accepted: 25 February 2021

Published: 3 March 2021

Publisher's Note: MDPI stays neutral with regard to jurisdictional claims in published maps and institutional affiliations.

Copyright: (c) 2021 by the authors. Licensee MDPI, Basel, Switzerland. This article is an open access article distributed under the terms and conditions of the Creative Commons Attribution (CC BY) license (https:// creativecommons.org/licenses/by/ $4.0 /)$.
Abstract: The effects of human disturbance represent one of the major threats for wildlife conservation. Many studies have shown that wildlife avoids or reduces direct contact with human activities through changes in activity patterns, and by minimizing spatiotemporal overlap. In this study, we investigated the possible effects of human presence on the temporal activity of medium-to-large mammals using two areas in Myanmar that differ in the intensity of human disturbance. We monitored temporal segregation mechanisms using camera trapping data and with two statistical approaches: daily activity overlaps between humans and wildlife and circular statistics. We did not find a significant difference in overlapping activity between areas but, thanks to circular statistics, we found that some species show changes in activity patterns, suggesting temporal avoidance. We observed that the daily activity of five species differed between areas of Myanmar, likely adopting mechanisms to reduce overlap in areas highly frequented by humans. Interestingly, these species are all threatened by hunting or poaching activities, four of which have been described in literature as "cathemeral", or species that are active through day and night. This study suggests that some species adapt their behavior, at least partially, to avoid human presence in habitats with higher anthropic occurrence and increase our knowledge on the status of medium-large mammals in a poorly studied country as Myanmar.

Keywords: activity patterns; camera trapping; human disturbance; mammals; spatial overlap; temporal segregation

\section{Introduction}

Tropical forests are one of the most threatened habitats in the world due to the increase of human activity, leading to forest fragmentation and habitat loss with drastic consequences for biodiversity [1]. One of the major threats for wildlife conservation is the degradation of ecosystems because of direct and indirect anthropogenic effects [2,3]. While some effects of human activity, such as habitat loss or wildlife population declines are evident, there are a multitude of other effects. These effects are often less studied and less evident including changes in species behaviors or interspecific interactions [4], or changes in space use and activity patterns [5]. Animals can adapt to changes in environment and availability of resources by varying their temporal activity patterns [6,7]. Many studies confirm that circadian patterns depend not only on internal factors, but also on external ones, such as prey availability, habitat selection, or niche differentiation [8,9]. In addition, 
circadian patterns can also be modified by human disturbances [10-15] or activities of domesticated animals as it was demonstrated for the disturbance by dogs [16-18]. In most environments, a constant human presence can interfere with wildlife communities. Indeed, humans may drive animals to change their behavior to avoid —or at least reduce-direct contact by minimizing spatiotemporal overlap and increasing avoidance [19]. Wildlife can adopt different mechanisms to reduce overlap with other species for space or other resources [20]; one of the most effective is the temporal segregation of a subordinate species with respect to a dominant one [21]. A shift in their daily activity patterns in response to the presence of other species has been demonstrated in a wide variety of natural populations [22-26]. Another mechanism is spatial segregation, which occurs when a species avoids a site or habitat occupied by a competitor or predator [27-30]. Finally, spatiotemporal segregation occurs when a species avoids a site only in the presence of another predator/competitor [31,32].

Among the tropical forests, the most affected are those of Southeast Asia. In particular, Myanmar is one of the countries with the highest deforestation and habitat degradation rates [33] combined with a local and international hunting pressure [34,35]. A large part of the human population in Myanmar (around 70\%) still live in rural areas with a consequent high use of forest resources [36]. Therefore, it is very important to study the status and distribution of wildlife populations in this poorly studied country to fill this lack of knowledge and to provide reliable data for real conservation actions. In this study, using camera traps, we investigated the temporal activity patterns in medium-to-large mammals, and their relationships to human activities. Camera traps are a useful instrument for wildlife monitoring as they offer accurate spatiotemporal data based on the spatial distribution (i.e., location) of camera traps and time-stamped images or videos [37]. Within our study areas, we evaluated different levels of human presence, and we checked for changes in animal activity patterns in areas highly and lowly frequented by humans. We analyzed temporal activity identifying daily activity patterns per species and assessing their overlap with human activity patterns. We also compared species activity in the two areas with circular statistics. Spatial segregation was not the main objective of this paper, but it has also been analyzed to further investigate human-wildlife interaction (unpublished data). We hypothesize that in sites with high human occurrence, temporal overlap between humans and wildlife should be lower than in sites with low anthropogenic occurrence. We also expected that where there is a stronger human pressure through hunting or poaching, target species would strongly avoid humans more than other species.

\section{Materials and Methods}

\subsection{Study Area}

Myanmar is the largest country in mainland SE Asia and hosts a wide range of habitats, supporting a rich but poorly studied biodiversity. More than half $(63 \%)$ of the mainland is covered by forests, but only $38 \%$ can be considered intact $[33,38,39]$. We conducted a camera trap survey in two different areas of Myanmar, characterized by differences in human presence and use of the area, being thus suitable for testing our hypotheses. The two areas share several ecological characteristics such as temperature range (annual mean: $20-22.5^{\circ} \mathrm{C}$ ), dominant habitat category (primarily evergreen forest; [40]), and altitudinal range (camera traps were positioned in a range of 100-200 $\mathrm{m}$ a.s.l.). However, the areas differ between levels of human disturbances and habitat integrity. The first area is located in Rakhine State (West Myanmar), which is near the border and partially inside the Rakhine Yoma Elephant Range Wildlife Reserve (RYER) in Gwa and Thandwe townships $\left(17^{\circ} 22^{\prime} 0^{\prime \prime} \mathrm{N}, 94^{\circ} 36^{\prime} 0^{\prime \prime} \mathrm{E}\right.$, Figure 1$)$. This area is characterized by habitat fragmentation with patches of evergreen forest alternating with mixed deciduous forest, bamboo brakes, and croplands. This area has been selected for its vulnerability to biodiversity loss due to human pressure [41]. The area is located close to the coast and densely populated, with heavy use and exploitation of forest resources [42]. The human activities consist of illegal 
logging (teak, padauk, and rosewood), and land use for cultivation (rubber trees and palm oil), illegal hunting of endangered species, or for bushmeat consumption [41].
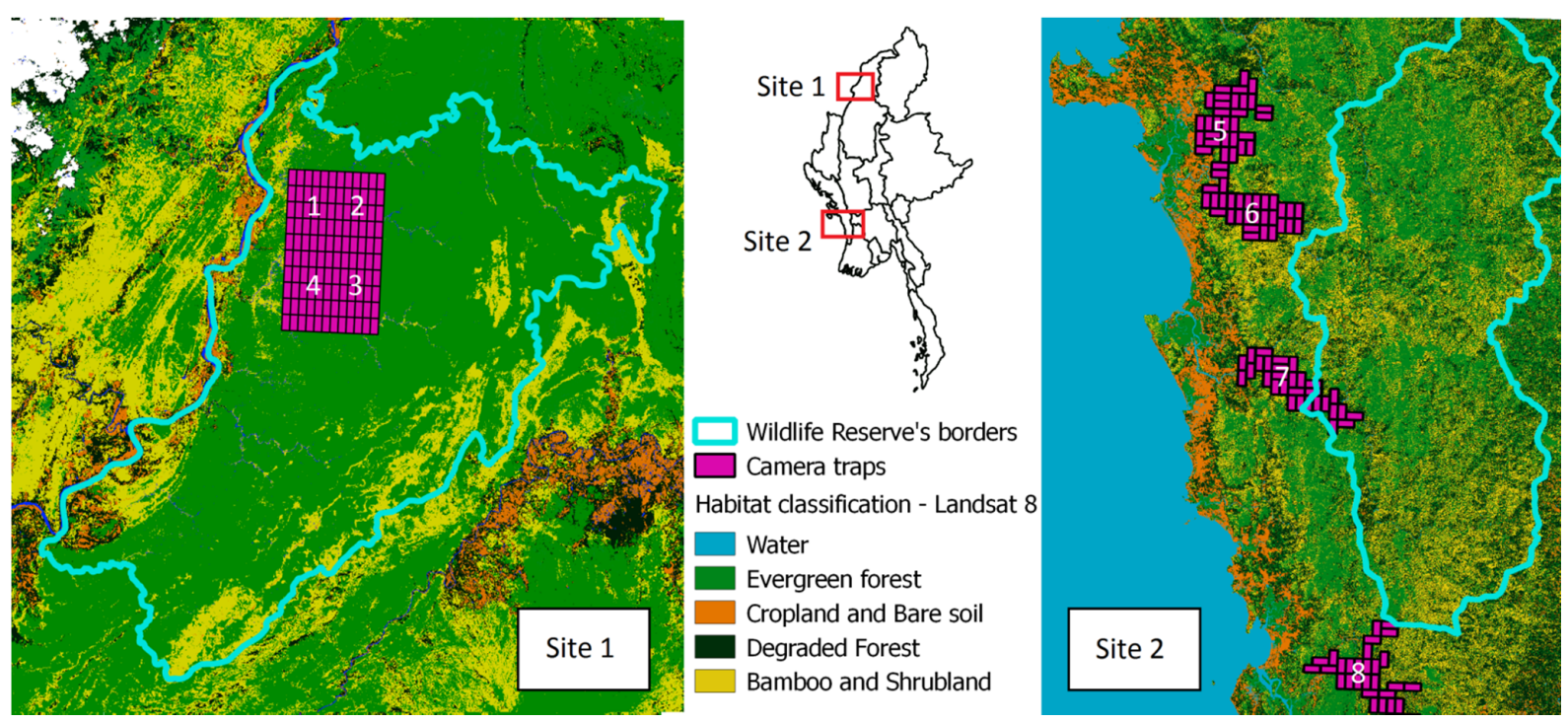

Figure 1. Location of study areas in Myanmar. On the (left), the detailed map of the sites in Sagaing State (1-4), inside the Htamanthi Wildlife Reserve (HWS). On the (right), the detailed map of camera trapping sites in Rakhine State (5-8), close to the protected area Rakhine Yoma Elephant Range (RYER). Land use and habitat types are also presented derived from land-cover map Landsat 8 OLI.

The second area is in Sagaing State (North Myanmar), inside the Htamanthi Wildlife Sanctuary (HWS) in Homalin and Hkamti townships $\left(25^{\circ} 37^{\prime} 39^{\prime \prime} \mathrm{N}, 95^{\circ} 54^{\prime} 23^{\prime \prime}\right.$ E, Figure 1). The area is part of Myanmar's northern forest complex, which probably is the single largest remaining forest in mainland SE Asia. This area is mostly covered by evergreen forest, mixed deciduous forest, and hill forest. It has been selected for the importance and the richness of its biodiversity and because it has maintained a much more natural, well preserved ecosystem compared to the first area. Human presence here is less widespread, since the study area is located inside the protected area. This provides greater protection from human presence and illegal activities consisting of few illegal logging and gold mining [41].

\subsection{Monitoring Plan}

Surveys were carried out during the dry season from November 2016 to April 2017 (year 1) and from November 2017 to April 2018 (year 2), since most of the forested areas are inaccessible in the rainy monsoon season. We selected four sampling sites in each area for a total of $480 \mathrm{~km}^{2}$ (average size of a sampling site: $60 \mathrm{~km}^{2}$ ). Each sampling site was further subdivided into 30 rectangular $2 \times 1 \mathrm{~km}$ plots, each monitored by at least one camera trap (Figure 1), for a total of 240 camera traps (Acorn Ltl-5210) each year. The cell design was selected according to environmental variable homogeneity and to facilitate the access as far as possible in the denser forest patches. In HWS, the sites are contiguous since the area inside the protected area is mostly covered by homogenous habitat (evergreen forest). In RYER, it is difficult to access forest patches making the four sites location distant from each other following mostly rivers to place camera in forest patches far from the coast. Since we only had 60 camera traps available for each area, a camera trap rotation scheme was devised. We had two sampling sites, out of four, with active camera traps in each area (simultaneously sampling two sites in RYER and two in HWS), for a minimum of 45 consecutive days and then moving traps into the other two sites (Supplementary Table S1). Data were downloaded every time the camera traps were repositioned from one site to the next. Each camera was positioned at an average height of $60 \mathrm{~cm}$ from the 
ground and was set up to record $20 \mathrm{~s}$ videos, at a $640 \times 480$ pixel resolution, with a $2 \mathrm{~min}$ interval between consecutive videos. Camera traps were configured to be active $24 \mathrm{~h}$ a day, with the passive infrared detector sensitivity level (PIR) set at "medium" with side PIR active [43]. No bait or attractant was used. All videos were stored on a dedicated Network Attached Storage server (Synology RS2416+, 43.5 TB total storage space), in separate directories hierarchically organized by study area, sampling site, and camera. Videos were then classified and when possible, we identified medium-large mammals at the species level as well as human presence. We also registered the presence of domestic dogs to understand whether dogs were related to human presence in our sampling sites, since it is common, especially in Rakhine, to hunt with them.

\subsection{Data Analysis}

All analyses were performed with the R software [44]. We carried out data analysis for species with at least 20 recorded events. We used all videos with a 2 min interval between consecutive videos. We considered it important to have a reasonably fine-grained sampling when studying activity patterns to better understand when animals are more active during the $24 \mathrm{~h}$. Since we considered sites in Rakhine as "high disturbance" and in Sagaing as "low disturbance" (see capture rates for Homo sapiens (Table 2)) we compared the means of camera trap rates in the two areas (divided by the total number of camera days in each sites) with the non-parametric Mann-Whitney U test. In addition, based on its activity pattern, a species was classified as "diurnal" ( $>80 \%$ of the recorded events occurred between 06:00 and 18:00), "nocturnal" (>80\% of recorded events between 18:00 and 06:00), or "cathemeral", species that are active both during day and night (difference between "diurnal" and "nocturnal" events as defined above: <20\%; Table 1) [45]. We compared our classification with available literature (Supplementary Table S2).

\subsection{Daily Activity Patterns}

We calculated and plotted the overall activity pattern for each species (as described in Rovero and Zimmermann [46]), using the number of recorded events per hour in both study areas for both monitoring seasons (Supplementary Figures S1 and S2). We then assessed daily activity pattern overlap following Meredith and Ridout [47]. For each species, we calculated the density function of events in $24 \mathrm{~h}$ (kernel density estimates), and then the proportion of overlap $\Delta$ (from 0 to 1, R overlap package, OverlapEst command, Ridout and Linkie [48]) between the kernel densities of pairs of species (same species between years; same species between areas and then species-humans, see below). As suggested by Massara et al. [21], we considered $\Delta \leq 0.5$ as the value indicating a low degree of overlap between two daily activity patterns, whereas $\Delta$ values between 0.5 and 0.6 indicated moderate overlap and $\Delta \geq 0.6$ indicated high overlap. We calculated the $95 \%$ confidence intervals for $\Delta$ estimates from 1000 bootstrap samples [47]. First we calculated, for each area separately, the overlap between the same species in the two different monitoring years to evaluate possible differences in daily activity patterns. The absence of differences $(\Delta \geq 0.5$; Supplementary Table S3) in the two sampling periods allowed us to pool data together for the temporal analysis suggesting there was no effect on differences in activity patterns based on the year (the only two species with $\Delta \leq 0.5$ were dhole in HWS and Asiatic golden cat in RYER; we decided to remove the first because of the very low overlap values, suggesting a year effect and we kept the second instead since it was marginally inferior to 0.5 , see Supplementary Table S3). Then, we selected species present in both areas and we calculated the intraspecific overlap between the two levels of intensity of human presence. Finally, we analyzed the overlap between each species with human activities to test if animals avoid humans in "high disturbance" areas, such as RYER, more than in "low disturbance" areas, such as HWS. The same analysis was done also between humans and domestic dogs to verify the potential relationship as explained above. A Paired $t$-test was used to assess if the two generated distributions of $\Delta$ (showing overlap between humans and each species) between the two areas were significantly different. We also investigated 
differences in activity patterns of species between the two different areas with circular statistic ( $\mathrm{R}$ package circular). The Mardia Wheeler W-test (MWW test) [49] was used to compare the distribution of detections amongst each species pair in the $24 \mathrm{~h}$, to test whether activity patterns differed significantly [50]. As described in Monterroso et al. [50], the MWW test is considered more appropriate in activity pattern studies to provide a threshold value to check significant differences between two activity patterns.

\section{Results}

During the first year, an average of 28 cameras in the eight sites were operating (we had some malfunctioning cameras) while in the second year, an average of 30 camera traps were used. The average days of operation for each camera was 54 days in year 1 and 49 days in year 2 (mean of total camera days of 12,345 each year). A total of 15,219 videos were recorded (year 1: 7779; year 2: 7440), not counting "empty" videos where the PIR sensor triggered the camera but no animal was recorded. A sample of 6464 were videos of wild medium-large mammals, humans, or domestic dogs (year 1: 3078; year 2: 3386). We identified 36 different species of medium-large mammals (included Homo sapiens and domestic dogs, Table 1).

Table 1. Checklist of medium-large mammals detected by camera traps from 2016 to 2018 at Rakhine Yoma Elephant Range (RYER) and Htamanthi Wildlife Sanctuary (HWS) in Myanmar. Activity pattern column shows how the species (with at least 20 detections) were classified according to detection times in the day (see Material and Methods for classification criteria). IUCN (2020) column shows the threat category of each species (LC = least concern; $\mathrm{NT}=$ near threatened; VU = vulnerable; $\mathrm{EN}=$ endangered; $\mathrm{CR}=$ critically endangered). Threats column shows the major threats for each species (IWT $=$ Illegal Wildlife Trade). In bold are shown the 19 species with at least 20 detections selected for the analysis.

\begin{tabular}{|c|c|c|c|c|c|}
\hline Latin Name & Common Name & Events & Activity Pattern & IUCN & Threats \\
\hline Homo sapiens & Human & 1882 & Diurnal & $\mathrm{LC}$ & / \\
\hline Muntiacus vaginalis & Northern red muntjak & 1063 & Diurnal & $\mathrm{LC}$ & Hunted for bushmeat \\
\hline Atherurus macrourus & $\begin{array}{l}\text { Asiatic brush-tailed } \\
\text { porcupine }\end{array}$ & 774 & Nocturnal & $\mathrm{LC}$ & Hunted for bushmeat \\
\hline Canis lupus familiaris & Domestic dog & 478 & Diurnal & $\mathrm{LC}$ & I \\
\hline Hystrix brachyura & Malayan porcupine & 362 & Nocturnal & $\mathrm{LC}$ & Hunted for bushmeat \\
\hline Sus scrofa & Wild pig & 323 & Diurnal & LC & Hunted for bushmeat \\
\hline $\begin{array}{l}\text { Paradoxurus } \\
\text { hermaphroditus }\end{array}$ & Asian palm civet & 240 & Nocturnal & $\mathrm{LC}$ & Hunted for bushmeat \\
\hline Viverra zibetha & Large Indian civet & 211 & Nocturnal & $\mathrm{LC}$ & Hunted for bushmeat \\
\hline Macaca arctoides & Stump-tailed macaque & 186 & Diurnal & VU & Poaching for IWT \\
\hline Helarctos malayanus & Sun bear & 165 & Cathemeral & VU & $\begin{array}{l}\text { Poaching for IWT and } \\
\text { Human-wildlife conflict }\end{array}$ \\
\hline Macaca leonina & $\begin{array}{l}\text { Northern pig-tailed } \\
\text { macaque }\end{array}$ & 138 & Diurnal & VU & Poaching for IWT \\
\hline Elephas maximus & Asian elephant & 117 & Nocturnal & EN & $\begin{array}{l}\text { Poaching for IWT and } \\
\text { Human-wildlife conflict }\end{array}$ \\
\hline Prionailurus bengalensis & Leopard cat & 103 & Nocturnal & $\mathrm{LC}$ & Poaching for IWT \\
\hline Neofelis nebulosa & Clouded leopard & 82 & Nocturnal & VU & Poaching for IWT \\
\hline Catopuma temminckii & Asiatic golden cat & 63 & Diurnal & NT & Poaching for IWT \\
\hline Martes flavigula & Yellow throated marten & 55 & Diurnal & LC & / $\quad 00$ \\
\hline Pardofelis marmorata & Marbled cat & 30 & Diurnal & NT & Poaching for IWT \\
\hline Cuon alpinus & Dhole & 24 & Diurnal & $\mathrm{EN}$ & $\begin{array}{l}\text { Poaching for IWT and } \\
\text { Human-wildlife conflict }\end{array}$ \\
\hline Rusa unicolor & Sambar & 23 & Nocturnal & VU & Hunted for bushmeat \\
\hline $\begin{array}{l}\text { Herpestes urva } \\
\text { Prionodon pardicolor }\end{array}$ & Crab-eating mongoose & 18 & Not classified & $\mathrm{LC}$ & / \\
\hline Prionodon pardicolor & Spotted linsang & 17 & Not classified & LC & Poaching for IWT and \\
\hline Panthera tigris & Tiger & 16 & Not classified & $\mathrm{EN}$ & Human-wildlife conflict \\
\hline $\begin{array}{l}\text { Capricornis rubidus } \\
\text { Melogale personata }\end{array}$ & $\begin{array}{l}\text { Red serow } \\
\text { Burmese ferret-badger }\end{array}$ & $\begin{array}{l}15 \\
13\end{array}$ & $\begin{array}{l}\text { Not classified } \\
\text { Not classified }\end{array}$ & $\begin{array}{l}\text { NT } \\
\text { LC }\end{array}$ & Hunted for bushmeat \\
\hline Bos gaurus & Gaur & 12 & Not classified & $\mathrm{VU}$ & $\begin{array}{l}\text { Hunted for bushmeat } \\
\text { and for IWT }\end{array}$ \\
\hline Arctonyx collaris & Hog badger & 10 & Not classified & VU & / \\
\hline Macaca mulatta & Rhesus macaque & 8 & Not classified & $\mathrm{LC}$ & / \\
\hline Manis javanica & Sunda pangolin & 8 & Not classified & CR & Poaching for IWT \\
\hline Manis pentadactyla & Chinese pangolin & 5 & Not classified & CR & Poaching for IWT \\
\hline Ursus thibetanus & Asian black bear & 5 & Not classified & VU & $\begin{array}{l}\text { Poaching for IWT and } \\
\text { Human-wildlife conflict }\end{array}$ \\
\hline Mustela strigidorsa & Back-striped weasel & 4 & Not classified & LC & / \\
\hline Paguma larvata & Masked palm civet & 4 & Not classified & $\mathrm{LC}$ & / \\
\hline Capricornis milneedwardsii & Chinese serow & 3 & Not classified & NT & Hunted for bushmeat \\
\hline Arctictis binturong & Binturong & 3 & Not classified & VU & Poaching for IWT \\
\hline Canis aureus & Golden jackal & 1 & Not classified & LC & / \\
\hline Viverricula indica & Small Indian civet & 1 & Not classified & $\mathrm{LC}$ & / \\
\hline
\end{tabular}


Their daily activity patterns (diurnal, nocturnal, cathemeral) were consistent with previously published assessments, except for Asiatic golden cat, sun bear, and Asian elephant (see below). The differences in human presence across our eight sites was evident for both years. Disturbance levels ranged from sites with no human-related events in Sagaing to sites that scored a maximum of 525 human-related events in Rakhine (site S005, see Table 2). Considering the total number of human events for both years, the mean of all the sites in RYER was significantly higher from the mean of all the sites in HWS (Mann-Whitney U test, $W=16 ; p=0.02$ ). In RYER, we found a total of 1882 human-related events, whereas sites in HWS we had a total of 61 human-related events. The activities found varied from mere presence or passage of humans (most of the videos) to some illegal activities such as logging (humans with chainsaws) or poaching (humans with guns). We did not divide the activities into different categories because we wanted to test if the generally high occurrence and frequency found in the forests, outside the RYER, could represent a disturbance for animals. Domestic dogs were only found in RYER with 478 videos in two years.

Table 2. Number of human detections for each site and the years at Htamanthi Wildlife Sanctuary (S001-S004) "low disturbance" area and Rakhine Yoma Elephant Range (S005-S008) "high disturbance" area. Data were obtained by camera trapping during dry seasons from 2016 to 2018.

\begin{tabular}{ccccccccc}
\hline Sites & S001 & S002 & S003 & S004 & S005 & S006 & S007 & S008 \\
\hline Year 1 & 0 & 15 & 0 & 10 & 525 & 118 & 47 & 231 \\
Year 2 & 8 & 10 & 4 & 14 & 315 & 122 & 298 & 164 \\
\hline Total & 8 & 25 & 4 & 24 & 840 & 240 & 345 & 395 \\
\hline
\end{tabular}

\section{Daily Activity Patterns}

We found 19 species with at least 20 independent events (Supplementary Figure S3). To study potential effects of human presence on wildlife activity, we selected only the 12 species (including $H$. sapiens and excluded dhole) that were present in both high and low human occurrence study sites. Time overlaps $(\Delta)$ between the same species activity patterns in the two study areas were moderate to high, showing no differences in species activity between RYER and HWS (Supplementary Figure S4). Instead, temporal overlap between species and human ranged from low, for nocturnal species such as Malayan porcupine $(\Delta<0.10)$, to high for diurnal species, such as Northern pig-tailed macaque $(\Delta>0.80)$ (Figure 2). Interestingly, domestic dogs were only found in RYER and presented quite a high overlap with human activities $(\Delta=0.78(0.72-0.91))$. However, in general, all species presented similar activity patterns between different disturbance levels. Across the 11 species occurring in both study areas, $\Delta$ activity overlap with humans did not differ between disturbance levels (Paired $t$-test, $t=-0.08, d f=11, p=0.93$ ). Differences in activity were found in five species with the MWW test: Asiatic golden cat $(W=8.32, d f=2$, $p=0.01)$, Asian elephant $(W=8.50, d f=2, p=0.01)$, sun bear $(W=6.92, d f=2, p=0.03)$, Northern pig-tailed macaque $(W=12.77, d f=2, p=0.001)$, and wild pig $(W=20.34, d f=2$, $p<0.0001)$. For these five species, the proportion of activity between night and day for the two disturbance levels is presented (Table 3). 
a

HIGH DISTURBANCE
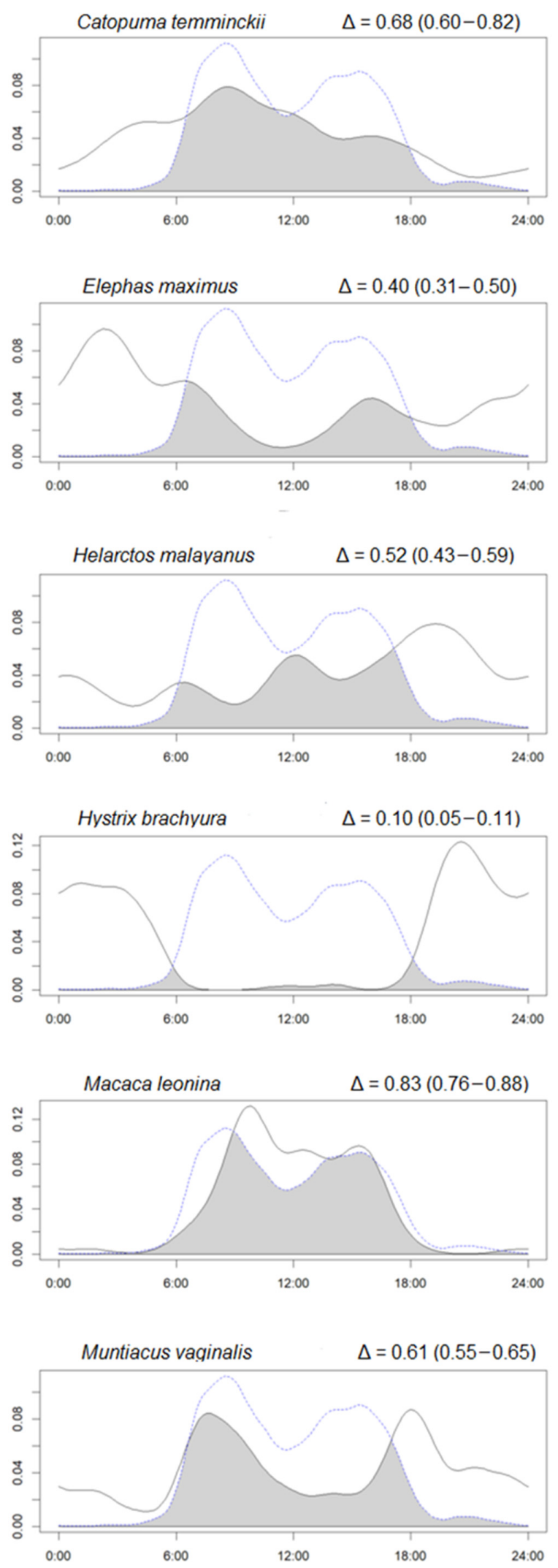

\section{LOW DISTURBANCE}
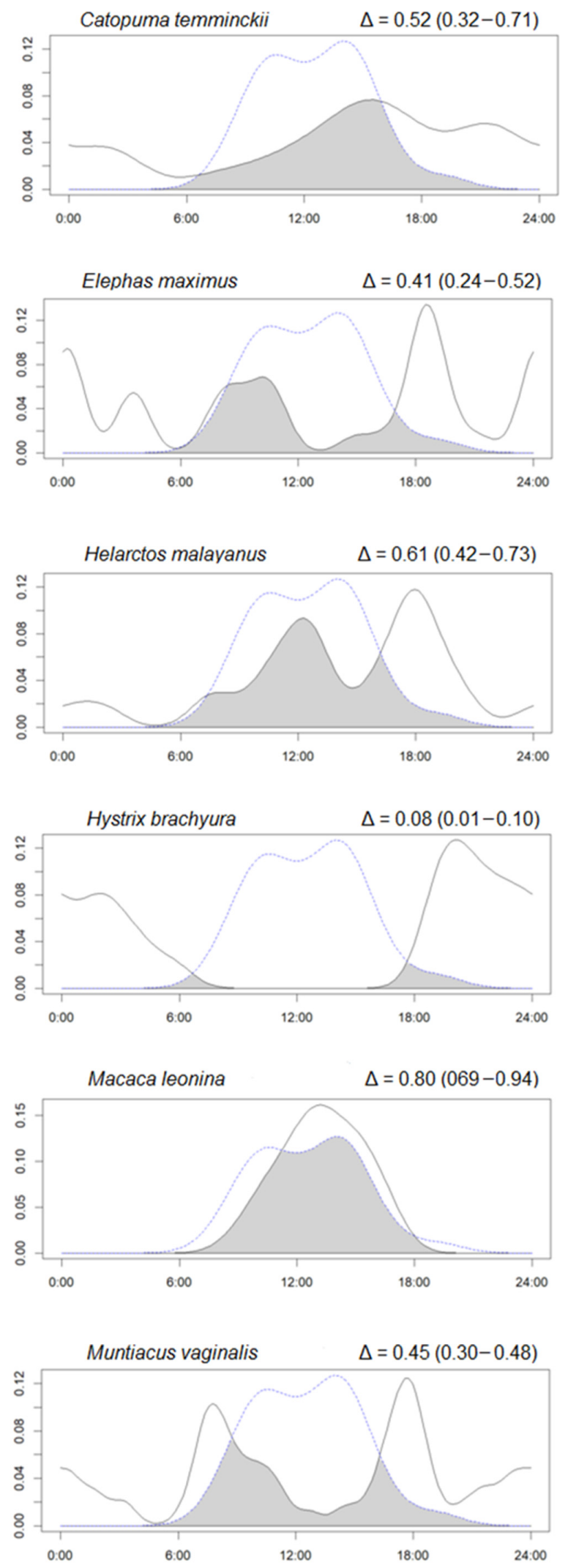

Figure 2. Cont. 


\section{b HIGH DISTURBANCE}
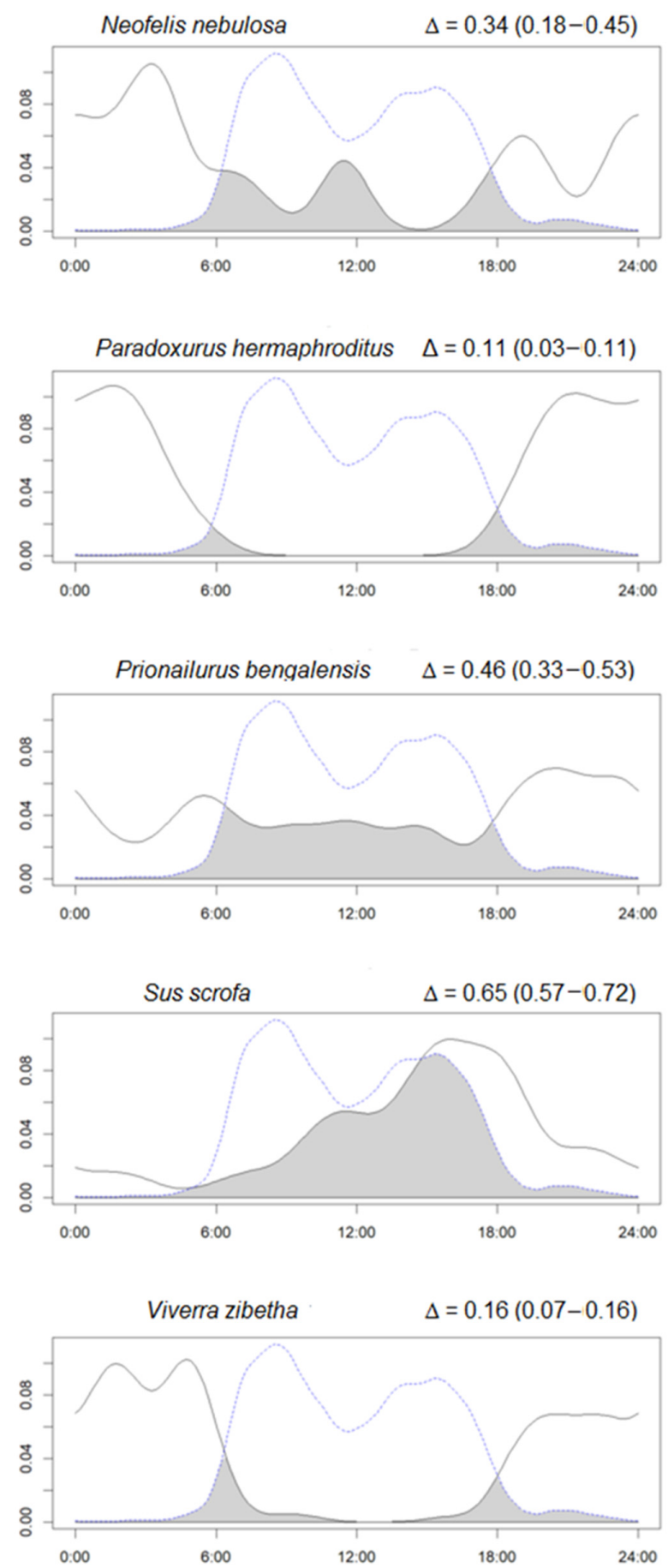

\section{LOW DISTURBANCE}
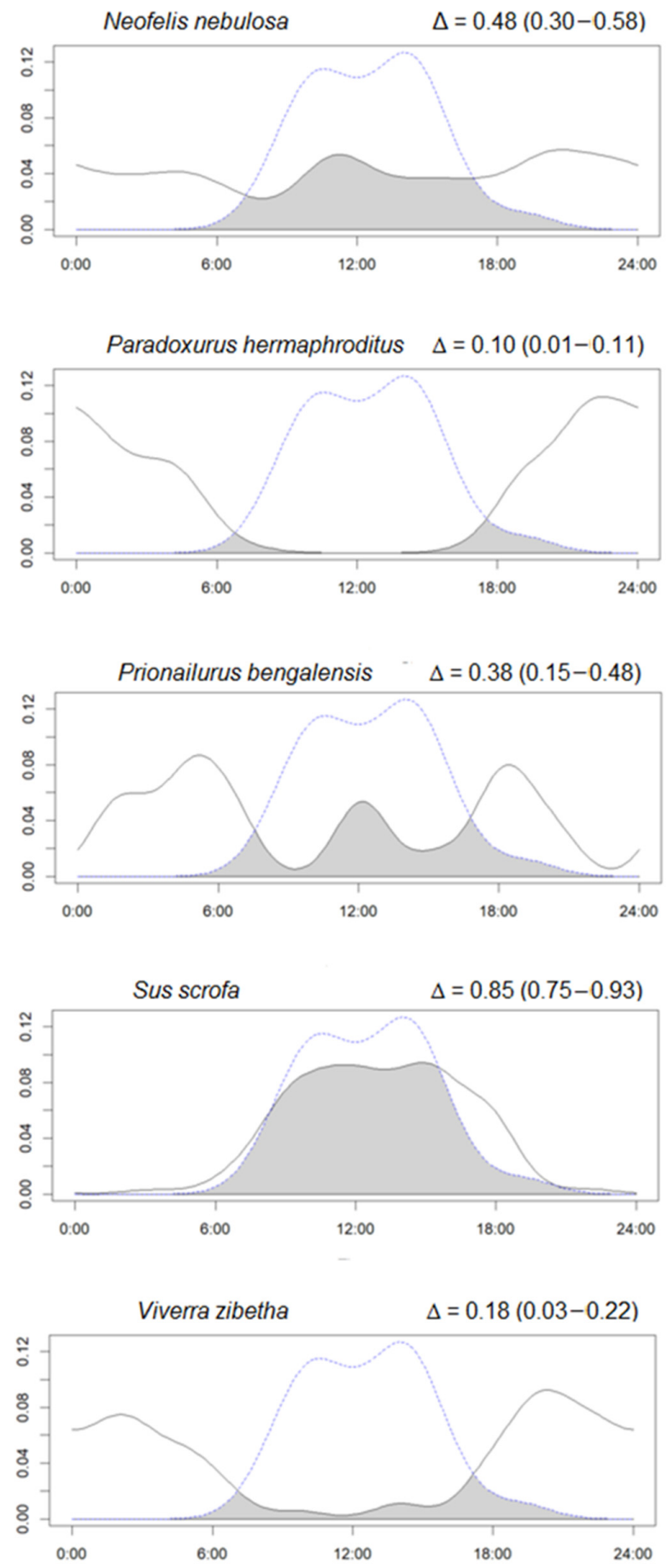

Figure 2. $(\mathbf{a}, \mathbf{b})$ Overlaps between the kernel density curve of the activity of species (continuous lines) and human activities (dotted lines) in a low human impact area (Sagaing, right side) compared to a high human impact area (Rakhine, left side). The area colored in dark grey represent the percentage of overlaps $(\Delta)$. The $\Delta$ values are followed by minimum and maximum confidence intervals in parentheses. The $\mathrm{X}$ axis reports the hours of the day and the $\mathrm{Y}$ the density of the activity in the $24 \mathrm{~h}$. 
Table 3. Proportion (\%) of activity between night and day in the two disturbance levels (high = Rakhine and low = Sagaing) for the five species for which the Mardia Wheeler W-test showed significantly different daily activity patterns between areas.

\begin{tabular}{lcccc}
\hline \multirow{2}{*}{ Species } & \multicolumn{2}{c}{ Low Disturbance } & \multicolumn{2}{c}{ High Disturbance } \\
\cline { 2 - 5 } & Diurnal & Nocturnal & Diurnal & Nocturnal \\
\hline Catopuma & $55 \%$ & $45 \%$ & $67 \%$ & $33 \%$ \\
temminckii & $34 \%$ & $66 \%$ & $36 \%$ & $64 \%$ \\
Elephas maximus & $70 \%$ & $30 \%$ & $48 \%$ & $52 \%$ \\
Helarctos & $100 \%$ & - & $96 \%$ & $4 \%$ \\
malayanus & $93 \%$ & $7 \%$ & $34 \%$ & $66 \%$ \\
Macaca leonina & & & & \\
Sus scrofa & & & & \\
\hline
\end{tabular}

\section{Discussion}

To investigate activity patterns of tropical species, often rare and elusive, camera traps are a useful instrument to achieve good sample sizes [51,52]. In our study, we found two completely different disturbance contexts to study the possible impact of human presence on wildlife activity. We had sites with minimum human activity, as well as sites constantly and intensively frequented by humans. As seen in other areas. we found that some species avoided humans by physically reducing the overlap of their activity pattern $[19,25,26]$. Even if the overlap between activity patterns of human and wild species were not significantly different between study areas, a more detailed analysis showed how the activity of five species differed between high and low disturbed areas. As documented in other studies, with an increase of human presence in the area, almost all of the species shifted to increased night-time activity [15]. The change in daily movements adopted by some of these species may reduce interactions with humans in areas with high levels of disturbance. Interestingly, in the literature, four species (sun bear, Asiatic golden cat, wild pig, and Asian elephant) are considered cathemeral [53]. However, our data suggest that these species can adapt to human presence in disturbed habitats through plasticity in their daily activity patterns. For all other species, our results showed similar activity patterns in areas with low and high human presence. This apparent lack of response to human disturbance might be explained by Myanmar tropical forests being subject to human disturbance for a long time. Many wildlife species developed high resilience to the constant presence of human activities [54,55]. Alternatively, some species are not sensitive to human presence in the area and can coexist in disturbed and frequented habitats.

\section{Daily Activity Patterns}

Human activities were concentrated during daily hours with two peaks corresponding with early morning and early afternoon. A very similar pattern was found for dogs (present only in RYER) suggesting that they often move together with humans. Thus, they can be considered as domestic dogs, often used for hunting in Myanmar [34,35], especially in Rakhine [56]. We have measured an extremely high human presence in the area of RYER in west Myanmar. With 1882 presence records, humans were the most detected species and the Northern red muntjak was the second with 1063 events. Despite this result, we found that the activity overlap between the same species in the two different disturbance levels were all moderate and high $(\Delta>0.50)$ suggesting small differences between areas. Apparently, the presence of human activity does not exert strong effects on wildlife activity patterns. We used the same method as Meredith and Ridout [47] to study daily activity patterns as many previous studies $[14,57,58]$. Based on the generated density function of the activity, we found no differences between activity pattern overlaps in the two disturbance conditions. However, looking at a more detailed scale using the MWW test (as also $[59,60]$ ), we found a significant difference between the activity peaks in the two disturbance levels for five species. Looking at these five species, we found that the Northern pig-tailed macaque had a strictly diurnal activity, the Asiatic golden cat and wild pig were classified as diurnal but 
with substantial activity also during night, the Asian elephant was classified as nocturnal but also active during daylight, and the sun bear was classified as only cathemeral. The MWW test results suggest that cathemeral species, moving if necessary during the day and night, are more adaptive and plastic and can easily change or shift their activity in relation to environmental disturbance, such as human activities. In addition, all these five species are threatened by different human activities, such as poaching, which may explain the shift in their activity. We found that wild pig (Red List IUCN category: LC) in HWS was mostly active during the day-time [61], but in RYER more than half of the contacts were nocturnal. The wild pig is one of the main hunting targets in Myanmar [62] and because of the consistent hunting activities in RYER, wild boars shift part of their activity to the night [45] as shown in the results. Northern pig-tailed macaque (VU) is strictly a diurnal animal [63] and in HWS, all records were during the day. In RYER, we also found some activity during the night which may be related to the intense human activity in this area. It will be interesting to investigate this pattern in detail since the species is categorized as Vulnerable by the IUCN [63] and it is already threatened by hunting and trade in some areas of Myanmar [62]. According to literature and confirmed in our study, sun bear (VU) can move during daylight [64] or during the night [65]. In RYER, sun bear had a prevalent nocturnal activity compared to HWS, where a peak of daily activity is evident (Figure 2). The sun bear is a target species in the illegal trade for Chinese traditional medicine [66] and is threatened by poaching, especially for their gall bladders and paws [67]. In contrast, the day-night activity of Asian elephant (EN) did not differ between regions, remaining mostly nocturnal in both areas. This pattern was documented also by Youngpoy [68] and Gray and Phan [45], however, Bhatt et al. [69] documented a diurnal activity but only in protected areas. In this study, the activity was mainly nocturnal in both regions, but in HWS we had two peaks of activity, in the morning and in late afternoon, explaining the significant difference revealed by the MWW test. Asian elephants, even if Myanmar is a cornerstone for this species [70], are threatened in the country by habitat degradation and fragmentation. This could potentially increase the risk of direct man-elephant conflicts [71], possibly explaining the shift to a predominant nocturnal activity in the disturbed area. Finally, Asiatic golden cat (NT) is described in the literature as an extremely adaptive species captured with camera traps during day and night [61,72]. In our study, we found a strong diurnal activity in both areas, with a difference in the peak of activity: morning in HWS and afternoon in RYER. This strong diurnal activity and this pattern cannot be directly related to human presence in the study area, although some illegal hunting for consumption has been documented [73]. A tentative explanation on why this cathemeral species was detected mostly during the day in our study areas was that often the same camera captured both Asiatic golden cat (during day) and clouded leopard (during night) suggesting a possible competition between two medium-sized felids with similar prey [74]. The same pattern was found also by [75] in Sumatra with a more diurnal activity for the Asiatic golden cat and a more nocturnal activity for the clouded leopard as an avoidance mechanism due to overlapping prey. It will be interesting to also investigate this pattern in the future but further analysis is needed.

Differences in daily activity patterns registered with circular statistics could also be explained by the seasonal differences in (mostly trophic) resource availability in the two regions. However, to verify this hypothesis, we would need to quantify resources availability in the field and through the different seasons. However, identifying what resources to measure without a clear knowledge of the species present is unfeasible and it is not always possible to access the study sites in certain seasons due to the extreme environmental conditions in tropical forests. The high number of environmental variables at play suggested that any differences in activity patterns could not depend on a single (or a few) "resources". In this work, we opted to focus not on environmental variables but on human presence and the resulting disturbance. Furthermore, dealing with a pool of five species with significantly different trophic positions, consisting of carnivores, herbivores, and omnivores, it can be assumed that the "resource availability" hypothesis cannot be the only 
factor influencing activity. In the future, it will be interesting to also investigate possible seasonal differences in relation to resource availability as in other studies $[7,76]$. We found that apart from a few cathemeral or target species (by hunting), the others did not show any temporal avoidance of human activities. These species, except the clouded leopard (VU), are all considered Least Concern by the IUCN (Malayan porcupine, Palm civet, Large Indian civet, leopard cat, and Northern red muntjak). A tentative explanation is that they developed resilience to humans, whose presence in forest environments started many years ago. The country had strong logging activity [77], particularly between 1990 and 2000 [78], and high deforestation rates are documented over the last twenty years [79]. As confirmed by Wang e Myint [80] particularly in RYER, in the period between 2001 and 2010, the annual rate of deforestation was $2.57 \%$ for a total loss of $3914 \mathrm{~km}^{2}$ of forest environments. Because of this, the mentioned species may have developed a more adaptable behavior in disturbed environments. It is known in literature that Malayan porcupines, palm civets, large Indian civets, leopard cats, and Northern red muntjaks are all species adapted to a wide range of habitats, even close to human settlements. Additionally, most of them have nocturnal behaviors [81-85]. Although the clouded leopard is strictly a nocturnal animal [86], it did not show a change in its activity during the night in either area due to the low presence of humans.

\section{Conclusions}

In conclusion, our hypothesis of a disturbance due to human presence on the daily activities of medium-large mammals was not confirmed for all the species that were monitored, but only for those with more plastic behavior and subject to more intensive human pressure. Evergreen forests, and forest habitats in general, are of chief importance both for humans and wildlife, and in the last decades these habitats have become one of the sites of the ongoing conflict linked to resource exploitation by humans. Our outcomes show, on one hand, that some species already developed forms of resilience, shifting their activity patterns in order to avoid human presence, and that ultimately forest mammal communities can adapt and thrive. On the other hand, the urgent need to develop sustainable practices also surfaced for the Rakhine area, where no data were previously available.

However, our data did not allow us to investigate possible indirect effects of human presence. The constant presence of humans in some areas is strictly related to logging and deforestation, and if logging continues at the current rate, huge habitat loss will directly eradicate some species. We retain that this study is an important initial documentation of the threat some species face due to human disturbances in a poorly studied country such as Myanmar. It can potentially provide fundamental information for developing specific action plans for threatened species as recently done for the sun bear [41]. Further investigation on species presence probability (e.g., occupancy studies) could help reveal these aspects and develop a better picture of human disturbance on wildlife also considering the possible spatial segregation.

Supplementary Materials: The following are available online at https:/ /www.mdpi.com/1999-4 907/12/3/290/s1, Table S1: Sampling effort per site and per session (year); Table S2: Daily activity patterns of target species according to results and literature; Table S3: Percentage of daily activity overlap (Delta) between year 1 and year 2; Figure S1: Activity patterns of the 19 mammals species recorded in both areas (Rakhine and Sagaing) the first year; Figure S2: Activity patterns of the 19 mammals species recorded in both areas (Rakhine and Sagaing) the second year; Figure S3: Activity patterns of the 19 mammals species recorded in both areas (Rakhine and Sagaing) with both years together; Figure S4: Overlap between the kernel density curve of the activity of the same species in a low and high human impact area.

Author Contributions: Conceptualization, methodology, and funding acquisition: F.B., H.N., K.M., Z.A., A.G., D.G.P., and A.M.; investigation: L.G., T.Z., K.M., and Z.A.; data curation and formal analysis: G.C., F.B., and L.A.W. All authors have read and agreed to the published version of the manuscript. 
Funding: This study was partially funded by Fondation Segré with the project "Conservation of Sun bears in Myanmar" and by Fondation Ensemble "Préservation de l'Ours malais dans le sud de l'Etat Rakhine (Arakan)".

Institutional Review Board Statement: Not applicable.

Informed Consent Statement: Not applicable.

Data Availability Statement: The datasets analyzed during the current study are available from the corresponding author on reasonable request.

Acknowledgments: We are grateful to the Ministry of Natural Resources and Environmental Conservation (MONREC) and to the Nature and Wildlife Conservation Division (NWCD) of Myanmar for their participation and for the constant support of the monitoring activities. We would like to thank the field staff consisting of U.W.L.A., U.T.T.W., U.M.P., and U.N.L. and the park rangers U.A.K.M., U.Y.W.N., and U.P.M.T. for their deep commitment they showed throughout the data collection in Rakhine. We would also like to thank the Wildlife Conservation Society (WCS) for their support and work in the region of Sagaing. Thanks also to the students S.L. and G.D.B. for helping in the data management and classification of the videos. A final thanks to Samantha Barnada and Andrew Isopi from the Department of Biochemistry and Molecular Biology at the Thomas Jefferson University for the careful and precise English revision they provided to us.

Conflicts of Interest: The authors declare no conflict of interest.

\section{References}

1. Lamb, D.; Erskine, P.D.; Parrotta, J.A. Restoration of Degraded Tropical Forest Landscapes. Science 2005, 310, 1628-1632. [CrossRef]

2. Cardinale, B.J. Biodiversity Loss and Its Impact on Humanity. Nature 2012, 486, 59. [CrossRef] [PubMed]

3. Hooper, D.U.; Adair, E.C.; Cardinale, B.J.; Byrnes, J.E.K.; Hungate, B.A.; Matulich, K.L.; Gonzalez, A.; Duffy, J.E.; Gamfeldt, L.; O'Connor, M.I. A Global Synthesis Reveals Biodiversity Loss as a Major Driver of Ecosystem Change. Nature 2012, 486, 105-108. [CrossRef] [PubMed]

4. Van Doormaal, N.; Ohashi, H.; Koike, S.; Kaji, K. Influence of Human Activities on the Activity Patterns of Japanese Sika Deer (Cervus Nippon) and Wild Boar (Sus Scrofa) in Central Japan. Eur. J. Wildl. Res. 2015, 61, 517-527. [CrossRef]

5. Ohashi, H.; Saito, M.; Horie, R.; Tsunoda, H.; Noba, H.; Ishii, H.; Kuwabara, T.; Hiroshige, Y.; Koike, S.; Hoshino, Y.; et al. Differences in the Activity Pattern of the Wild Boar Sus Scrofa Related to Human Disturbance. Eur. J. Wildl. Res. 2013, 59, 167-177. [CrossRef]

6. Phillips, A.J.K.; Fulcher, B.D.; Robinson, P.A.; Klerman, E.B. Mammalian Rest/Activity Patterns Explained by Physiologically Based Modeling. PLoS Comput. Biol. 2013, 9, e1003213. [CrossRef] [PubMed]

7. Caravaggi, A.; Gatta, M.; Vallely, M.-C.; Hogg, K.; Freeman, M.; Fadaei, E.; Dick, J.T.A.; Montgomery, W.I.; Reid, N.; Tosh, D.G. Seasonal and Predator-Prey Effects on Circadian Activity of Free-Ranging Mammals Revealed by Camera Traps. Peer J. 2018, 6, e5827. [CrossRef] [PubMed]

8. Lucherini, M.; Reppucci, J.I.; Walker, R.S.; Villalba, M.L.; Wurstten, A.; Gallardo, G.; Iriarte, A.; Villalobos, R.; Perovic, P. Activity Pattern Segregation of Carnivores in the High Andes. J. Mammal. 2009, 90, 1404-1409. [CrossRef]

9. Ferreguetti, A.C.; Davis, C.L.; Tomas, W.M.; Bergallo, H.G. Using Activity and Occupancy to Evaluate Niche Partitioning: The Case of Two Peccary Species in the Atlantic Rainforest, Brazil. Hystrix 2018, 29, 168-174. [CrossRef]

10. Riley, S.P.D.; Sauvajot, R.M.; Fuller, T.K.; York, E.C.; Kamradt, D.A.; Bromley, C.; Wayne, R.K. Effects of Urbanization and Habitat Fragmentation on Bobcats and Coyotes in Southern California. Conserv. Biol. 2003, 17, 566-576. [CrossRef]

11. Di Bitetti, M.S.; Paviolo, A.; Ferrari, C.A.; De Angelo, C.; Di Blanco, Y. Differential Responses to Hunting in Two Sympatric Species of Brocket Deer (Mazama Americana and M. Nana). Biotropica 2008, 40, 636-645. [CrossRef]

12. Podgórski, T.; Baś, G.; Jędrzejewska, B.; Sönnichsen, L.; Śnieżko, S.; Jędrzejewski, W.; Okarma, H. Spatiotemporal Behavioral Plasticity of Wild Boar (Sus Scrofa) under Contrasting Conditions of Human Pressure: Primeval Forest and Metropolitan Area. J. Mammal. 2013, 94, 109-119. [CrossRef]

13. Díaz-Ruiz, F.; Caro, J.; Delibes-Mateos, M.; Arroyo, B.; Ferreras, P. Drivers of Red Fox (Vulpes Vulpes) Daily Activity: Prey Availability, Human Disturbance or Habitat Structure? J. Zool. 2016, 298, 128-138. [CrossRef]

14. Oberosler, V.; Groff, C.; Iemma, A.; Pedrini, P.; Rovero, F. The Influence of Human Disturbance on Occupancy and Activity Patterns of Mammals in the Italian Alps from Systematic Camera Trapping. Mammal. Biol. 2017, 87, 50-61. [CrossRef]

15. Gaynor, K.M.; Hojnowski, C.E.; Carter, N.H.; Brashares, J.S. The Influence of Human Disturbance on Wildlife Nocturnality. Science 2018, 360, 1232-1235. [CrossRef] [PubMed]

16. Vanak, A.T.; Gompper, M.E. Interference Competition at the Landscape Level: The Effect of Free-ranging Dogs on a Native Mesocarnivore. J. Appl. Ecol. 2010, 47, 1225-1232. [CrossRef]

17. Zapata-Ríos, G.; Branch, L.C. Altered Activity Patterns and Reduced Abundance of Native Mammals in Sites with Feral Dogs in the High Andes. Biol. Conserv. 2016, 193, 9-16. [CrossRef] 
18. Mella-Méndez, I.; Flores-Peredo, R.; Pérez-Torres, J.; Hernández-González, S.; González-Uribe, D.U.; Bolívar-Cimé, B.S. Activity Patterns and Temporal Niche Partitioning of Dogs and Medium-Sized Wild Mammals in Urban Parks of Xalapa, Mexico. Urban. Ecosyst. 2019, 22, 1061-1070. [CrossRef]

19. Carter, N.; Jasny, M.; Gurung, B.; Liu, J. Impacts of People and Tigers on Leopard Spatiotemporal Activity Patterns in a Global Biodiversity Hotspot. Glob. Ecol. Conserv. 2015, 3, 149-162. [CrossRef]

20. Niedballa, J.; Wilting, A.; Sollmann, R.; Hofer, H.; Courtiol, A. Assessing Analytical Methods for Detecting Spatiotemporal Interactions between Species from Camera Trapping Data. Remote Sens. Ecol. Conserv. 2019, 5, 272-285. [CrossRef]

21. Massara, R.L.; de Oliverira Paschoal, A.M.; Bailey, L.L.; Doherty, P.F.; de Frias Barreto, M.; Chiarello, A.G. Effect of Humans and Pumas on the Temporal Activity of Ocelots in Protected Areas of Atlantic Forest. Mammal. Biol. 2018, 92, 86-93. [CrossRef]

22. Ngoprasert, D.; Lynam, A.J.; Gale, G.A. Human Disturbance Affects Habitat Use and Behaviour of Asiatic Leopard Panthera Pardus in Kaeng Krachan National Park, Thailand. Oryx 2007, 41, 343-351. [CrossRef]

23. Linkie, M.; Ridout, M.S. Assessing Tiger-Prey Interactions in Sumatran Rainforests: Tiger-Prey Temporal Interactions. J. Zool. 2011, 284, 224-229. [CrossRef]

24. Foster, V.C.; Sarmento, P.; Sollmann, R.; Tôrres, N.; Jácomo, A.T.A.; Negrões, N.; Fonseca, C.; Silveira, L. Jaguar and Puma Activity Patterns and Predator-Prey Interactions in Four Brazilian Biomes. Biotropica 2013, 45, 373-379. [CrossRef]

25. Ross, J.; Hearn, A.J.; Johnson, P.J.; Macdonald, D.W. Activity Patterns and Temporal Avoidance by Prey in Response to Sunda Clouded Leopard Predation Risk: Activity of Sunda Clouded Leopards and Their Prey. J. Zool. 2013, 290, 96-106. [CrossRef]

26. Davison, C.W.; Chapman, P.M.; Wearn, O.R.; Bernard, H.; Ewers, R.M. Shifts in the Demographics and Behavior of Bearded Pigs (Sus Barbatus) across a Land-use Gradient. Biotropica 2019, 51, 938-948. [CrossRef]

27. MacKenzie, D.I.; Bailey, L.L.; Nichols, J.D. Investigating Species Co-Occurrence Patterns When Species Are Detected Imperfectly. J. Anim. Ecol. 2004, 73, 546-555. [CrossRef]

28. MacKenzie, D.I.; Nichols, J.D.; Royle, J.A.; Pollock, K.H.; Bailey, L.A.; Hines, J.E. Occupancy Modeling and Estimation: Inferring Patterns and Dynamics of Species Occurrence; Academic Press: Cambridge, MA, USA, 2006.

29. Richmond, O.M.W.; Hines, J.E.; Beissinger, S.R. Two-Species Occupancy Models: A New Parameterization Applied to CoOccurrence of Secretive Rails. Ecol. Appl. 2010, 20, 2036-2046. [CrossRef] [PubMed]

30. De Matos Dias, D.; Lima Massara, R.; de Campos, C.B.; Henrique Guimarães Rodrigues, F. Human Activities Influence the Occupancy Probability of Mammalian Carnivores in the Brazilian Caatinga. Biotropica 2019, 51, 253-265. [CrossRef]

31. Kronfeld-Schor, N. Partitioning of Time as an Ecological Resource. Ann. Rev. Ecol. Evol. Syst. 2003, 34, 153-181. [CrossRef]

32. Schuette, P.; Wagner, A.P.; Wagner, M.E.; Creel, S. Occupancy Patterns and Niche Partitioning within a Diverse Carnivore Community Exposed to Anthropogenic Pressures. Biol. Conserv. 2013, 158, 301-312. [CrossRef]

33. Bhagwat, T.; Hess, A.; Horning, N.; Khaing, T.; Thein, Z.M.; Aung, K.M.; Aung, K.H.; Phyo, P.; Tun, Y.L.; Oo, A.H.; et al. Losing a Jewel-Rapid Declines in Myanmar's Intact Forests from 2002-2014. PLoS ONE 2017, 12, e0176364. [CrossRef] [PubMed]

34. McEvoy, J.F.; Connette, G.; Huang, Q.; Soe, P.; Pyone, K.H.H.; Valitutto, M.; Htun, Y.L.; Lin, A.N.; Thant, A.L.; Htun, W.Y.; et al. Two Sides of the Same Coin-Wildmeat Consumption and Illegal Wildlife Trade at the Crossroads of Asia. Biol. Conserv. 2019, 238, 108197. [CrossRef]

35. Smiley Evans, T.; Myat, T.W.; Aung, P.; Oo, Z.M.; Maw, M.T.; Toe, A.T.; Aung, T.H.; Hom, N.S.; Shein, K.T.; Thant, K.Z.; et al. Bushmeat Hunting and Trade in Myanmar's Central Teak Forests: Threats to Biodiversity and Human Livelihoods. Glob. Ecol. Conserv. 2020, 22, e00889. [CrossRef]

36. Than, K. The Status of the Agricultural Sector in Myanmar in 2004. In Myanmar's Long Road to National Reconciliation; ISEAS-Yusof Ishak Institute: Singapore, 2006.

37. Rowcliffe, J.M.; Kays, R.; Carbone, C.; Jansen, P.A. Clarifying Assumptions behind the Estimation of Animal Density from Camera Trap Rates: Density Estimates from Camera Trap Rates. J. Wildl. Manag. 2013, 77, 876. [CrossRef]

38. Zhang, Y.; Prescott, G.W.; Tay, R.E.; Dickens, B.L.; Webb, E.L.; Htun, S.; Tizard, R.J.; Rao, M.; Carrasco, L.R. Dramatic Cropland Expansion in Myanmar Following Political Reforms Threatens Biodiversity. Sci. Rep. 2018, 8, 16558. [CrossRef]

39. Reddy, C.S.; Pasha, S.V.; Satish, K.V.; Unnikrishnan, A.; Chavan, S.B.; Jha, C.S.; Diwakar, P.G.; Dadhwal, V.K. Quantifying and Predicting Multi-Decadal Forest Cover Changes in Myanmar: A Biodiversity Hotspot under Threat. Biodivers. Conserv. 2019, 28, 1129-1149. [CrossRef]

40. Istituto Oikos; BANCA. Myanmar Protected Areas Context, Current Status and Challenges; Ancora Libri: Milano, Italy, 2011.

41. Gaffi, L.; Zibordi, F.; Cremonesi, G.; Bisi, F.; Tizard, R.J.; Naing, H.; Moe, K.; Htun, S.; Beffasti, L. Sun Bear Conservation Action Plan: 2020-2029-RYER and Htamanthi WS; Istituto Oikos: Milano, Italy, 2020.

42. Myanmar Ministry of Health. Health in Myanmar 2011. Technical Report. Available online: https://www.mohs.gov.mm/Main/ content/publication/health-in-myanmar-2011 (accessed on 26 January 2021).

43. Bisi, F.; Cremonesi, G.; Gaffi, L.; Zibordi, F.; Gagliardi, A.; Gueli, L.; Martinoli, A.; Preatoni, D.G. Watching a Movie or Going for a Walk? Testing Different Sun Bear (Helarctos Malayanus) Occupancy Monitoring Schemes. Hystrix 2019, 30, 178-182.

44. R Development Core Team. R: A Language and Environment for Statistical Computing; R Foundation for Statistical Computing: Vienna, Austria, 2018.

45. Gray, T.N.; Phan, C. Habitat preferences and activity patterns of the larger mammal community in Phnom Prich Wildlife Sanctuary, Cambodia. Raffl. Bull. Zool. 2011, 59, 311-318.

46. Rovero, F.; Zimmermann, F. Camera Trapping for Wildlife Research; Pelagic Publishing Ltd.: Exeter, UK, 2016. 
47. Meredith, M.; Ridout, M. Overview of the Overlap Package. 2016, pp. 1-9. Available online: https:// cran.r-project.org/web/ packages/overlap/vignettes/overlap.pdf (accessed on 29 January 2021).

48. Ridout, M.S.; Linkie, M. Estimating Overlap of Daily Activity Patterns from Camera Trap Data. J. Agric. Biol. Environ. Stat. 2009, 14, 322-337. [CrossRef]

49. Batschelet, E. Circular Statistics in Biology; Academic Press: New York, NY, USA, 1981; p. 388.

50. Monterroso, P.; Alves, P.C.; Ferreras, P. Plasticity in Circadian Activity Patterns of Mesocarnivores in Southwestern Europe: Implications for Species Coexistence. Behav. Ecol. Sociobiol. 2014, 68, 1403-1417. [CrossRef]

51. Haidir, I.A.; Macdonald, D.W.; Linkie, M. Assessing the Spatiotemporal Interactions of Mesopredators in Sumatra's Tropical Rainforest. PLoS ONE 2018, 13, e0202876. [CrossRef] [PubMed]

52. Marinho, P.H.; Bezerra, D.; Antongiovanni, M.; Fonseca, C.R.; Venticinque, E.M. Activity Patterns of the Threatened Northern Tiger Cat Leopardus Tigrinus and Its Potential Prey in a Brazilian Dry Tropical Forest. Mammal. Biol. 2018, 89, 30-36. [CrossRef]

53. Tattersall, I. The Concept of Cathemerality: History and Definition. Folia Primatol. 2006, 77, 7-14. [CrossRef] [PubMed]

54. Griffiths, M.; Schaik, C.P. The Impact of Human Traffic on the Abundance and Activity Periods of Sumatran Rain Forest Wildlife. Conserv. Biol. 1993, 7, 623-626. [CrossRef]

55. Weaver, J.L.; Paquet, P.C.; Ruggiero, L.F. Resilience and Conservation of Large Carnivores in the Rocky Mountains. Conserv. Biol. 1996, 10, 964-976. [CrossRef]

56. Platt, S.G.; Ko, W.K.; Khaing, L.L.; Myo, K.M.; Swe, T.; Lwin, T.; Rainwater, T.R. Population Status and Conservation of the Critically Endangered Burmese Star Tortoise Geochelone Platynota in Central Myanmar. Oryx 2003, 37, 464-471. [CrossRef]

57. Carter, N.H.; Shrestha, B.K.; Karki, J.B.; Pradhan, N.M.B.; Liu, J. Coexistence between Wildlife and Humans at Fine Spatial Scales. Proc. Natl. Acad. Sci. USA 2012, 109, 15360-15365. [CrossRef] [PubMed]

58. Frey, S.; Fisher, J.T.; Burton, A.C.; Volpe, J.P. Investigating Animal Activity Patterns and Temporal Niche Partitioning Using Camera-Trap Data: Challenges and Opportunities. Remote Sens. Ecol. Conserv. 2017, 3, 123-132. [CrossRef]

59. Pratas-Santiago, L.P.; Gonçalves, A.L.S.; da Maia Soares, A.M.V.; Spironello, W.R. The Moon Cycle Effect on the Activity Patterns of Ocelots and Their Prey. J. Zool. 2016, 299, 275-283. [CrossRef]

60. Mori, E.; Bagnato, S.; Serroni, P.; Sangiuliano, A.; Rotondaro, F.; Marchianò, V.; Cascini, V.; Poerio, L.; Ferretti, F. Spatiotemporal Mechanisms of Coexistence in an European Mammal Community in a Protected Area of Southern Italy. J. Zool. 2020, 310, 232-245. [CrossRef]

61. Kawanishi, K.; Sunquist, M. Food habits and activity patterns of the Asiatic golden cat (Catopuma temminckii) and dhole (Cuon alpinus) in a primary rainforest of Peninsular Malaysia. Mammal. Study 2008, 33, 173-177. [CrossRef]

62. Bisi, F.; Gagliardi, A.; Cremonesi, G.; Colombo, R.; Mazzamuto, M.V.; Wauters, L.A.; Preatoni, D.G.; Martinoli, A. Distribution of Wildlife and Illegal Human Activities in the Lampi Marine National Park (Myanmar). Environ. Conserv. 2019, 46, 163-170. [CrossRef]

63. Boonratana, R.; Chetry, D.; Long, Y.; Jiang, X.L.; Htun, S.; Timmins, R.J. Macaca leonine (Errata Version Published in 2020). In The IUCN Red List of Threatened Species; IUCN: Gland, Switzerland, 2020; e.T39792A186071807. [CrossRef]

64. Wong, S.T.; Servheen, C.; Ambu, L.; Norhayati, A. Impacts of Fruit Production Cycles on Malayan Sun Bears and Bearded Pigs in Lowland Tropical Forest of Sabah, Malaysian Borneo. J. Trop. Ecol. 2005, 21, 627-639. [CrossRef]

65. Guharajan, R.; Arnold, T.W.; Bolongon, G.; Dibden, G.H.; Abram, N.K.; Teoh, S.W.; Magguna, M.A.; Goossens, B.; Wong, S.T.; Nathan, S.K.S.S.; et al. Survival Strategies of a Frugivore, the Sun Bear, in a Forest-Oil Palm Landscape. Biodivers. Conserv. 2018, 27, 3657-3677. [CrossRef]

66. Burgess, E.; Stoner, S.; Foley, K. Brought to Bear: An Analysis of Seizures across Asia (2000-2011); TRAFFIC Southeast Asia: Petaling Jaya, Selangor, Malaysia, 2014.

67. Scotson, L.; Fredriksson, G.; Augeri, D.; Cheah, C.; Ngoprasert, D.; Wai-Ming, W. Helarctos malayanus (Errata Version Published in 2018). In The IUCN Red List of Threatened Species; IUCN: Gland, Switzerland, 2017; e.T9760A123798233. [CrossRef]

68. Youngpoy, N. Population and Activities of Wild Elephants (Elephas Maximus) in Salakphan Wildlife Sanctuary, Kanchanaburi Province, Thailand. Ph.D. Thesis, Mahidol University, Nakhon Pathom, Thailand, 2012.

69. Bhatt, U.M.; Habib, B.; Sarma, H.K.; Lyngdoh, S.L. Catch Me If You Can: Species Interactions and Moon Illumination Effect on Mammals of Tropical Semi-Evergreen Forest of Manas National Park, Assam, India. bioRxiv 2018. [CrossRef]

70. Kusza, S.; Suchentrunk, F.; Pucher, H.; Mar, K.U.; Zachos, F.E. High Levels of Mitochondrial Genetic Diversity in Asian Elephants (Elephas Maximus) from Myanmar. Hystrix 2018, 29, 152-154.

71. Hedges, S.; Tyson, M.J.; Sitompul, A.F.; Hammatt, H. Why Inter-Country Loans Will Not Help Sumatra's Elephants. Zoo. Biol. 2006, 25, 235-246. [CrossRef]

72. Mohd, A.J.; Sharma, D.S.K. The Diversity and Activity Patterns of Wild Felids in a Secondary Forest in Peninsular Malaysia. Oryx 2006, 40, 36-41. [CrossRef]

73. Khan, M. The neglected Asiatic golden cats of Bangladesh. Cat News 2008, 48, 20-21.

74. Haidir, I.A.; Dinata, Y.; Linkie, M.; Macdonald, D.W. Asiatic golden cat and Sunda clouded leopard occupancy in the Kerinci Seblat landscape, West-Central Sumatra. Cat News 2013, 59, 7-10.

75. Sunarto, S.; Kelly, M.J.; Parakkasi, K.; Hutajulu, M.B. Cat Coexistence in Central Sumatra: Ecological Characteristics, Spatial and Temporal Overlap, and Implications for Management: Cat Coexistence Ecology in Sumatra. J. Zool. 2015, 296, 104-115. [CrossRef] 
76. Martin, E.H.; Ndibalema, V.G.; Rovero, F. Does Variation between Dry and Wet Seasons Affect Tropical Forest Mammals' Occupancy and Detectability by Camera Traps? Case Study from the Udzungwa Mountains, Tanzania. Afr. J. Ecol. 2017, 55, 37-46. [CrossRef]

77. Saung, T.; Khai, T.C.; Mizoue, N.; Ota, T.; Kajisa, T. Condition of Illegally Logged Stands Following High Frequency Legal Logging in Bago Yoma, Myanmar. Forests 2021, 12, 115. [CrossRef]

78. Mon, M.S.; Mizoue, N.; Htun, N.Z.; Kajisa, T.; Yoshida, S. Factors Affecting Deforestation and Forest Degradation in Selectively Logged Production Forest: A Case Study in Myanmar. Forest Ecol. Manag. 2012, 267, 190-198. [CrossRef]

79. Leimgruber, P.; Kelly, D.S.; Steininger, M.K.; Brunner, J.; Müller, T.; Songer, M. Forest Cover Change Patterns in Myanmar (Burma) 1990-2000. Environ. Conserv. 2005, 32, 356-364. [CrossRef]

80. Wang, C.; Myint, S. Environmental Concerns of Deforestation in Myanmar 2001-2010. Remote Sens. 2016, 8, 728. [CrossRef]

81. Timmins, R.J.; Steinmetz, R.; Samba Kumar, N.; Anwarul Islam, M.D.; Sagar Baral, H. Muntiacus vaginalis. In The IUCN Red List of Threatened Species; IUCN: Gland, Switzerland, 2016; e.T136551A22165292. [CrossRef]

82. Lunde, D.; Aplin, K.; Molur, S. Hystrix brachyura (Errata Version Published in 2017). In The IUCN Red List of Threatened Species; IUCN: Gland, Switzerland, 2016; e.T10749A115099298. [CrossRef]

83. Duckworth, J.W.; Timmins, R.J.; Choudhury, A.; Chutipong, W.; Willcox, D.H.A.; Mudappa, D.; Rahman, H.; Widmann, P.; Wilting, A.; Xu, W. Paradoxurus hermaphroditus. In The IUCN Red List of Threatened Species; IUCN: Gland, Switzerland, 2016; e.T41693A45217835. [CrossRef]

84. Ross, J.; Brodie, J.; Cheyne, S.; Hearn, A.; Izawa, M.; Loken, B.; Lynam, A.; McCarthy, J.; Mukherjee, S.; Phan, C.; et al. Prionailurus bengalensis. In The IUCN Red List of Threatened Species; IUCN: Gland, Switzerland, 2015; e.T18146A50661611. [CrossRef]

85. Timmins, R.J.; Duckworth, J.W.; Chutipong, W.; Ghimirey, Y.; Willcox, D.H.A.; Rahman, H.; Long, B.; Choudhury, A. Viverra zibetha. In The IUCN Red List of Threatened Species; IUCN: Gland, Switzerland, 2016; e.T41709A45220429. [CrossRef]

86. Grassman, L.; Lynam, A.; Mohamad, S.; Duckworth, J.W.; Bora, J.; Wilcox, D.; Ghimirey, Y.; Reza, A.; Rahman, H. Neofelis nebulosa. In The IUCN Red List of Threatened Species; IUCN: Gland, Switzerland, 2016; e.T14519A97215090. [CrossRef] 